\title{
Obituary
}

\section{Professor John Anthony (Sean) Spence}

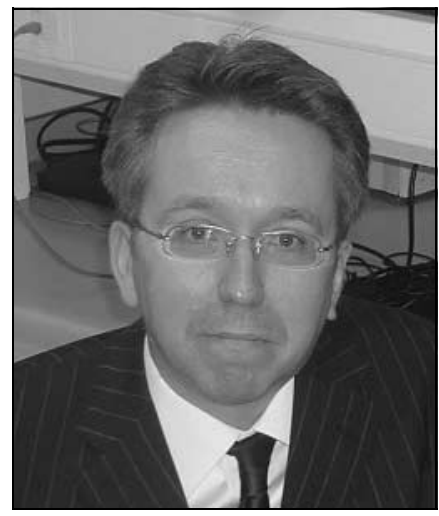

Formerly Professor of Academic Clinical Psychiatry, Sheffield University

Sean Spence was born on 8 June 1962 in Barnet, London. He attended St Mary's School, Sidcup, and completed an intercalated BSc in psychology before graduating in medicine at Guy's, King's and St Thomas' School of Medicine, London. Then, as a number of psychiatrists have done, he 'matured' into the specialty after obtaining postgraduate diplomas in obstetrics and gynaecology and general practice. Psychiatry for Sean seemed to embody his range of interests in human activity. One of these was music - he was himself an accomplished jazz musician and had recorded an album, and he continued to maintain an interest as patron of Huddersfield Contemporary Music Festival and Sheffield Jazz and Swing Festival. Another keen interest was in literature, particularly philosophy, including philosophy of action. Sean was one of a 100 'free thinkers' identified by BBC Radio 3 in 2008, and brought to bear his interest in morality and volition through his research and teaching. He organised highly successful symposia that focused on such varied topics as psychiatry and the problem of evil and psychiatry and the unconscious. His imagination and flair for writing were widely appreciated and produced often provocative titles such as 'The illusion of Conscious Will' and 'Bad or Mad?', as well as general articles for the informed reader such as 'Jason Bourne's amnesia - in 100 words'. He wrote regular contributions to the British Medical Journal.

Psychiatry allowed Sean an expression of passionate interest in, and research of, the human condition on the one hand and the alleviation of human suffering on the other. In research, he was inspired to investigate the underlying causes of problems faced by people who have schizophrenia. While a research fellow, he was interested in the neural basis of volition, and developed ideas as to how individuals with schizophrenia lost their sense of agency and experienced passivity. An important contribution at this time included evidence for the potential to recover from 'hypofrontality' in schizophrenia. Sean's interest in volition and 'free will' continued to develop, and once established at Sheffield University in the Academic Clinical Psychiatry Department and the Sheffield Cognition and Neuroimaging Laboratory (SCANLab), he published landmark papers that helped define the sequence of events in the brain which lead to spontaneous and willed actions. These ideas were also translated into identifying the potential therapeutic effects of modafinil on prefrontal cortical function in individuals with schizophrenia.

Latterly, Sean moved into the less extensively explored area of deception research, where his interest in 'free will' and morality came together with that in brain imaging and the potential forensic settings where 'lie detection' could have a place. He was, however, suitably circumspect in this potential application and he recognised that much more research was needed to identify the processes that lead to deception as well as to verify accuracy of the means of predicting deceptive behaviour. However, some useful, and characteristically cautious, early steps were taken in the mapping of a biology of deception. Sean's ideas for how this might be developed were contained within one of his papers, 'Looking for truth and finding lies: the prospects for a nascent neuroimaging of deception'.

Following his MRC training fellowship and the completion of a scholarship at the Cornell Medical College in New York, USA, in 2000 Sean joined the Academic Clinical Psychiatry Department at Sheffield University as a Senior Clinical Lecturer. There he was awarded an MRC Career Establishment Award, and promoted to Reader in 2002 and to Professor in 2005. As a clinical academic he always took clinical work very seriously and was latterly in charge of the Homeless

Assessment and Support Team for Sheffield Health and Social Care NHS Foundation Trust. Here, he attended to some of the neediest people in society with characteristic diligence and rigour, insisting on detailed clinical assessment and follow-up often under difficult circumstances.

In 2008, Sean developed metastatic colonic cancer which proved fatal. During his illness he was able for a period to continue working part-time, attempting to complete his most important work. His deception work reached a natural conclusion, although he would have liked to extend it into the next phase. His work on schizophrenia, however, left a large data-set largely un-analysed and yet to meet the light of day. Sean died on 25 December 2010.

Peter W. R. Woodruff doi: $10.1192 / p b . b p .111 .035766$ 